\title{
Early Reconstruction of Orbital Roof Fractures: Clinical Features and Treatment Outcomes
}

\author{
Jin Woo Kim, Tae Hui Bae, Woo Seob Kim, Han Koo Kim \\ Department of Plastic and Reconstructive Surgery, Chung-Ang University Hospital, Chung-Ang University College of Medicine, Seoul, Korea
}

Background Orbital roof fractures are frequently associated with a high energy impact to the craniofacial region, and displaced orbital roof fractures can cause ophthalmic and neurologic complications and occasionally require open surgical intervention. The purpose of this article was to investigate the clinical features and treatment outcomes of orbital root fractures combined with neurologic injuries after early reconstruction.

Methods Between January 2006 and December 2008, 45 patients with orbital roof fractures were admitted; among them, 37 patients were treated conservatively and 8 patients underwent early surgical intervention for orbital roof fractures. The type of injuries that caused the fractures, patient characteristics, associated fractures, ocular and neurological injuries, patient management, and treatment outcomes were investigated.

Results The patients underwent frontal craniotomy and free bone fragment removal, their orbital roofs were reconstructed with titanium micromesh, and associated fractures were repaired. The mean follow up period was 11 months. There were no postoperative neurologic sequelae. Postoperative computed tomography scans showed anatomically reconstructed orbital roofs. Two of the five patients with traumatic optic neuropathy achieved full visual acuity recovery, one patient showed decreased visual acuity, and the other two patients completely lost their vision due to traumatic optic neuropathy. Preoperative ophthalmic symptoms, such as proptosis, diplopia, upper eyelid ptosis, and enophthalmos were corrected. Conclusions Early recognition and treatment of orbital roof fractures can reduce intracranial and ocular complications. A coronal flap with frontal craniotomy and orbital roof reconstruction using titanium mesh provides a versatile method and provides good functional and cosmetic results.

Keywords Orbital fracture / Postoperative complication / Optic nerve
Correspondence: Tae Hui Bae Department of Plastic and Reconstructive Surgery, Chung-Ang University Hospital, Chung-Ang University College of Medicine, 102 Heukseok-ro, Dongjak-gu, Seoul 156-755, Korea

Tel: +82-2-6299-1615

Fax: +82-2-825-9880

E-mail: psbth@cau.ac.kr
No potential conflict of interest relevant to this article was reported.

\section{INTRODUCTION}

Orbital roof fractures in adults are uncommon and are usually associated with high-impact injuries to the head and face. Nondisplaced or minimally displaced orbital roof fractures are usually managed by observation [1], but displaced orbital roof fractures can cause ophthalmic and neurologic complications and open surgical intervention is occasionally required [2].

Early reconstruction, within 10 days of trauma, by stabilizing the midfacial fractures, makes anatomical reconstruction possible because bone margins remain intact [3] and because early reconstruction also helps to prevent secondary operations and

Copyright () 2012 The Korean Society of Plastic and Reconstructive Surgeons

This is an Open Access article distributed under the terms of the Creative Commons Attribution Non-Commercial License (http://creativecommons.org/

licenses/by-nc/3.0/) which permits unrestricted non-commercial use, distribution, and reproduction in any medium, provided the original work is properly cited.

www.e-aps.org 
reduce the risk of infection [4]. Surgical treatment requires teamwork by neurosurgeons, plastic surgeons, and ophthalmologists. Careful ocular and neurologic examinations are important to avoid ocular and intracranial complications. The purpose of this study was to investigate the clinical features and treatment outcomes of orbital roof fractures combined with craniofacial trauma after early reconstruction.

\section{METHODS}

From January 2006 to December 2008, 45 patients with orbital roof fractures (4\%) among 1,145 patients with a facial or skull fracture were admitted to the Department of Neurosurgery and the Department of Plastic Surgery at our hospital. Thirty-seven of the $45(82 \%)$ were managed conservatively for their orbital roof fractures and showed completely recovery within 1 month without any complications. The other 8 patients (18\%) underwent early surgical intervention for their orbital roof fractures from within hours of injury to 11 days after injury. Combined neurosurgical and ophthalmologic intervention was required in patients with destructive lesions of the brain and clear mechanical compression of the optic nerve by displaced fracture fragments. Seven patients underwent immediate surgical reduction and fixation of the orbital roof fractures at the time of admission because of the presence of multiple craniofacial fractures associated with intracranial injuries. In one patient, surgery was delayed until 11 days after admission because of an unstable vital status.

In all patients, frontal craniotomy using a bicoronal approach was performed. After retraction of the brain and exposure of the anterior cranial fossa, intracranial injuries such as dura tears and intracranial hematomas were repaired or removed. After neurologic repair, the displaced orbital roof bone fragments were removed and optic nerve decompression was performed when a bone fragment compressed the optic nerve. The orbital roofs were reconstructed using three-dimensionally fabricated titanium micromesh plates and microscrews, and the associated fractures were then repaired.

Preoperative neurological and ophthalmic examinations included visual acuity, pupillary response to light, extraocular muscle movement, exophthalmometry, and a fundus examination. All patients underwent three dimensional facial computed tomography (CT) scans. The type of injuries responsible for the fractures, patient characteristics, associated fractures, ocular and neurological injuries, patient management, and treatment outcomes were investigated.

\section{RESULTS}

Male patients predominated (M:F ratio 7:1) and their ages ranged from 18 to 41 years (mean, 24 years). Additional facial and other body fractures were also encountered, such as those of the zygoma-maxilla (four patients), orbit (three patients), upper extremities (three patients), lower extremities (two patients), ribs (two patients), spine (one patient), and nasal bone (one patient). All patients presented with supraorbital rim fractures associated with roof fractures and other frontal bone fractures. Associated neurologic and ophthalmologic injuries, clinical features, and treatment outcomes are summarized in Table 1. The follow-up period was 6 to 29 months (average, 11 months). No patient developed postoperative neurologic sequelae, such as cranial nerve dysfunction, cerebrospinal fluid (CSF) leaks, or meningitis. Postoperative CT scans showed anatomically reconstructed orbital roofs in all cases (Fig. 1). One patient with an

Table 1. Summary of the clinical features and treatment outcomes

\begin{tabular}{|c|c|c|c|c|}
\hline $\begin{array}{l}\text { Patient } \\
\text { (Sex/Age) }\end{array}$ & Cause of injury & $\begin{array}{l}\text { Associated ocular } \\
\text { findings }\end{array}$ & $\begin{array}{l}\text { Associated neurologic } \\
\text { injuries }\end{array}$ & Postoperative outcome \\
\hline $\mathrm{M} / 26$ & Motor cycle accident & No light perception, proptosis, OD & $\begin{array}{l}\text { Frontal bone fracture, } \\
\text { hemorrhagic contusion }\end{array}$ & $\begin{array}{l}\text { Normal visual acuity }(0.8,0 D) \text {, } \\
\text { resolution of proptosis }\end{array}$ \\
\hline $\mathrm{M} / 33$ & Falls & Proptosis, diplopia, OD & Frontal bone fracture, EDH & $\begin{array}{l}\text { Resolution of proptosis, } \\
\text { diplopia }\end{array}$ \\
\hline M/35 & Motor cycle accident & Pulsating proptosis, OS & $\begin{array}{l}\text { Frontal bone fracture, } \\
\text { hemorrhagic contusion }\end{array}$ & Resolution of proptosis \\
\hline M/39 & Falls & $\begin{array}{l}\text { No light perception, } \\
\text { blepharoptosis, enophthalmos, } \\
\text { OD }\end{array}$ & $\begin{array}{l}\text { Frontal bone fracture, } \\
\text { hemorrhagic contusion }\end{array}$ & $\begin{array}{l}\text { Normal visual acuity }(1.0,0 D), \\
\text { residual enophthalmos, } \\
\text { diplopia }\end{array}$ \\
\hline $\mathrm{M} / 41$ & Falls & No light perception, OD & $\begin{array}{l}\text { Frontal bone fracture, } \\
\text { EDH }\end{array}$ & Amblyopia $(0.25,0 D)$ \\
\hline$M / 24$ & Motor cycle accident & No light perception, OD & Frontal bone fracture, EDH & Blindness \\
\hline $\mathrm{M} / 18$ & Motor cycle accident & Eye globe rupture, OD & Frontal bone fracture & Exenteration of eye globe \\
\hline $\mathrm{F} / 19$ & Motor cycle accident & No light perception, proptosis, OD & Frontal bone fracture, EDH & $\begin{array}{l}\text { Blindness, resolution of } \\
\text { proptosis }\end{array}$ \\
\hline
\end{tabular}




\section{Fig. 1. Case}

(A) Preoperative axial view of CT scans of a 26-year-old man showing a displaced orbital roof fracture fragment compressing the optic nerve. (B) Preoperative coronal CT scans showing a displaced orbital roof fracture fragment compressing the optic nerve. (C) Preoperative sagittal CT scans showing a displaced orbital roof fracture fragment compressing the optic nerve (white arrow). (D) Preoperative three-dimensional (3D) facial CT scans showing a displaced orbital roof fracture fragment compressing the optic nerve. (E) Postoperative axial CT scans showing the orbital roof, which was anatomically reconstructed using titanium micro mesh. (F) Postoperative coronal CT scans showing the orbital roof, which was anatomically reconstructed using titanium micro mesh. (G) Postoperative sagittal CT scans showing the orbital roof, which was anatomically reconstructed using titanium micro mesh. (H) Postoperative 3D facial CT scans showing the orbital roof, which was anatomically reconstructed using titanium micro mesh.
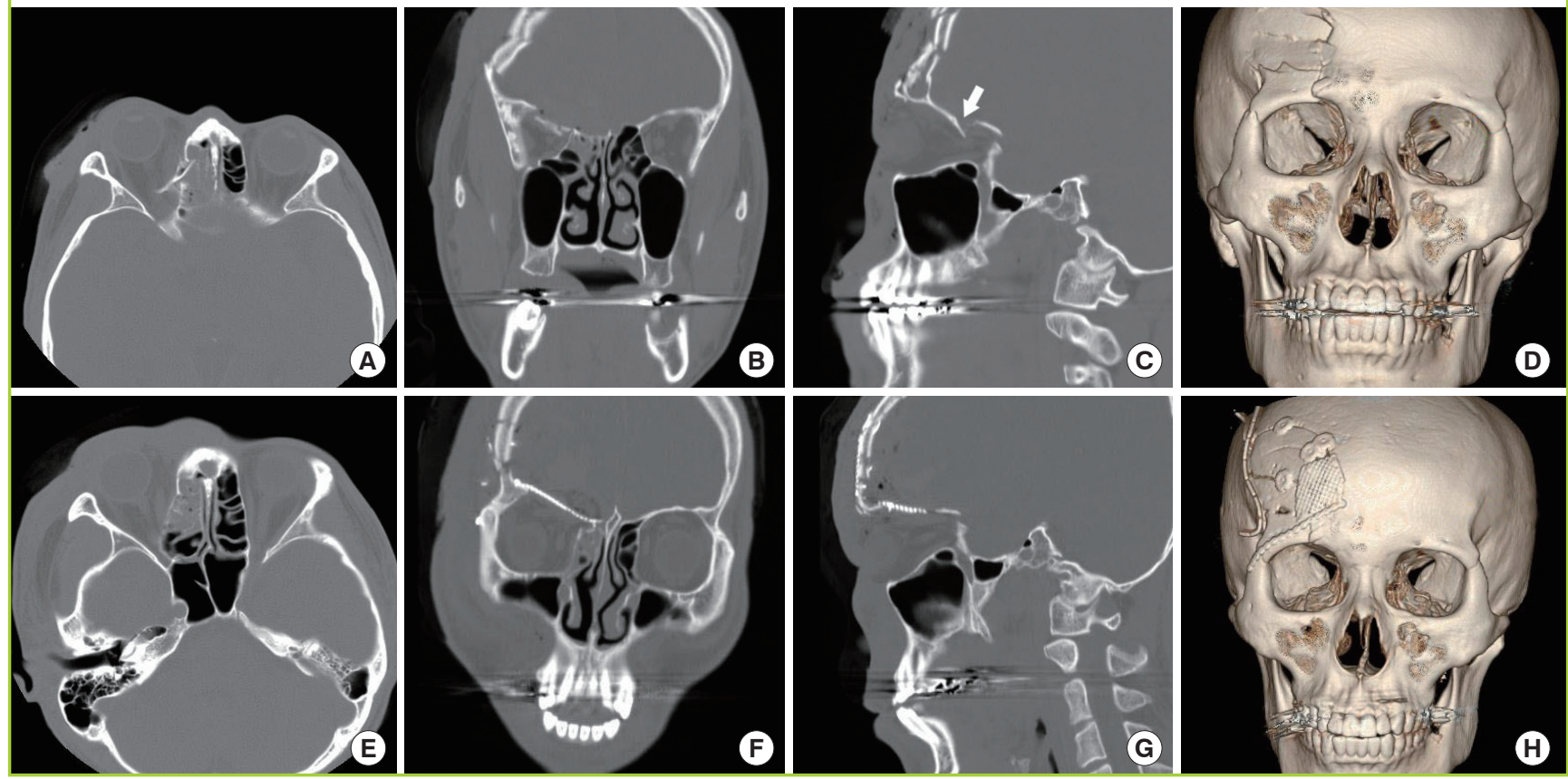

eye globe rupture underwent exenteration of the globe during surgery by the ophthalmic department. Two of the five patients with traumatic optic neuropathy achieved full visual acuity recovery, one patient showed decreased visual acuity, and the other two patients completely lost their vision due to traumatic optic neuropathy. Preoperative ophthalmic symptoms such as proptosis, diplopia, upper eyelid ptosis, and enophthalmos were corrected. One patient with orbital apex syndrome demonstrated full visual acuity recovery with subjective diplopia improvement and underwent ophthalmic surgery for paralytic strabismus 27 months later.

\section{DISCUSSION}

Orbital roof fractures present challenging situations to surgeons. Isolated orbital roof fractures are considered rare, and the majorities are associated with other forms of neurologic injury. Orbital roof fractures have been reported to account for between $1 \%$ and $9 \%$ of facial bone fractures $[5,6]$. In our series, they composed $4 \%$ of all facial bone fractures. Orbital roof fractures are often the result of high-energy impacts, such as those resulting from motor vehicle accidents, falls, or bludgeoning with a blunt

object [5,7], although infants have a relatively high incidence of orbital roof fractures because of the lack of a pneumatized frontal sinus [8]. Nondisplaced or minimally displaced orbital roof fractures generally do not require surgical intervention and are usually managed by observation [1]. On the other hand, displaced orbital roof fractures have the potential to result in significant neurologic, ophthalmologic, and cosmetic morbidities, such as proptosis, blindness, globe rupture, eye immobility, anesthesia or paresthesia of the supraorbital and supratrochlear nerves, CSF leakage, intracranial injury, enophthalmos, exophthalmos, ectropion, entropion, infection, diplopia, restricted extraocular movements, blepharoptosis, orbital volume discrepancy, and those associated with the presence of foreign bodies [5].

Orbital roof fractures that result from frontal trauma are usually severe and often involve accompanying intracranial injury. Furthermore, surgical approaches to orbital roof fractures present significant risks of intracranial infections because of the proximity of the orbital roof and frontal sinuses, concomitant dura tears, and CSF leaks associated with pneumocephalus [9]. Accordingly, surgical approaches require multimodal strategies involving neurosurgeons, plastic surgeons, and ophthalmologists. Moreover, immediate surgical intervention is often nec- 
essary for neurosurgical and ophthalmic reasons. A variety of approaches exist for obtaining access to the anterior skull base, such as lateral eyebrow incision, upper eyelid incision, and coronal incision.

A coronal incision with frontal craniotomy provides a sufficiently wide exposure for dural repair and orbital roof reconstruction [10]. After completing neurosurgical repair, the damaged orbital roof can be reduced and reconstructed. Autogenous substances, such as the calvarium, rib, and ilium, are difficult to mold to the anatomical contours of the orbit, and their resorption rates are unpredictable. Furthermore, it is difficult to make alloplastic materials that maintain the appropriate contours, and they introduce the risk of infection. In our series, we reconstructed orbital roofs with titanium micromesh and microscrew systems. Titanium mesh and microscrew systems are highly versatile, easy to handle, and lack the problems associated with other materials. In particular, these meshes are malleable enough to be adapted intimately to the contours of the bony orbit, substantial enough to provide the support required, and do not interfere with postoperative imaging [7].

In the present study, we did not encounter any significant postoperative neurological complications such as a CSF leak or meningitis. Piotrowski and Beck-Mannagetta [3] reported that about $80 \%$ of patients obtained good overall functional and cosmetic results after early surgical intervention. In the other $20 \%$, unsatisfactory results were mainly due to a primary traumatic injury to the orbit such as motility restrictions, enophthalmos, and optic nerve injury. Fulcher and Sullivan [8] reported that outcomes were favorable in patients with vertical diplopia who had delayed surgery. However, urgent orbital intervention is indicated for ophthalmic emergencies such as eye globe perforation, retrobulbar hematoma, and fracture of the optic canal associated with a displaced bony fragment causing traumatic optic neuropathy [11]. Furthermore, large displaced fracture segments not treated promptly can lead to orbital encephalocele, as was reported by Messinger et al. [9].

The best treatment method for traumatic optic neuropathy and visual acuity recovery remains controversial. The three major therapeutic options for traumatic optic neuropathy are megadose corticosteroids, surgical optic canal decompression, or combinations of the two. Optic nerve decompression should not be undertaken as an elective procedure or on an unconscious patient. Furthermore, if loss of vision is associated with a nonreactive pupil, and this loss occurred at the moment of impact, the procedure is probably not going to result in improvement. On the other hand, if loss of vision or the loss of papillary response to light develops after the moment of impact, conducting surgery with the intention of improving the situa- tion should be considered. However, if it cannot be determined whether loss of vision or papillary response was delayed, the patient should be observed for 4 to 6 days, and if spontaneous improvement occurs, no surgery should be undertaken. If no improvement occurs, it might be reasonable to decompress the optic canal. Some authors favor a more rapid progression to decompression, the rationale being that optic nerve decompression will reduce bone fragment impingement on the optic nerve and open the canal to reduce compression on a swollen optic nerve and its vascular supply within the optic canal. In our series, clinical and radiologic evidence of a basilar skull fracture with destructive brain lesions and preoperative CT scans revealed that a displaced bone fragment compressed the optic nerve in 5 patients with traumatic optic neuropathy, and that in these patients a combined neurosurgical/ophthalmologic approach was indicated. If a patient's general condition permits, and there are no significant additional risks, surgical treatment should proceed as soon as possible, as prompt surgery could improve both functional and cosmetic results. When an optic nerve injury is presented at the time of initial evaluation and is due to bone fragments on or near to the optic nerve, an attempt should be made to remove these fragments during the initial surgical management effort; high dose steroids and optic nerve decompression may also improve results.

The treatment of orbital roof fractures should be individualized and be based on the nature of displacement, the association between the skull and frontal sinus fractures, and the presence of dural tears and intracranial hemorrhage. The authors suggest that when displaced orbital roof fractures are associated with ophthalmic and neurological injuries, early surgical intervention can minimize postoperative morbidity and improve functional and cosmetic results.

Early recognition and treatment of orbital roof fractures can reduce the incidences of intracranial and ocular complications. Furthermore, we emphasize the importance of a combined approach involving plastic surgeons, neurosurgeons, and ophthalmologists. A coronal flap with frontal craniotomy and orbital roof reconstruction using titanium mesh offers a versatile method and provides good functional and cosmetic results.

\section{REFERENCES}

1. Bolling JP, Wesley RE. Conservative treatment of orbital roof blow-in fracture. Ann Ophthalmol 1987;19:75-6.

2. Sullivan WG. Displaced orbital roof fractures: presentation and treatment. Plast Reconstr Surg 1991;87:657-61.

3. Piotrowski WP, Beck-Mannagetta J. Surgical techniques in orbital roof fractures: early treatment and results. J Cranio- 
maxillofac Surg 1995;23:6-11.

4. Converse JM, Hogan VM. Open-sky approach for reduction of naso-orbital fractures: case report. Plast Reconstr Surg 1970;46:396-8.

5. Haug RH, Nuveen E, Bredbenner T. An evaluation of the support provided by common internal orbital reconstruction materials. J Oral Maxillofac Surg 1999;57:564-70.

6. Greenwald MJ, Boston D, Pensler JM, et al. Orbital roof fractures in childhood. Ophthalmology 1989;96:491-6.

7. Rinna C, Rocchi G, Ventucci E, et al. Bilateral orbital roof fracture. J Craniofac Surg 2009;20:737-42.
8. Fulcher TP, Sullivan TJ. Orbital roof fractures: management of ophthalmic complications. Ophthal Plast Reconstr Surg 2003;19:359-63.

9. Messinger A, Radkowski MA, Greenwald MJ, et al. Orbital roof fractures in the pediatric population. Plast Reconstr Surg 1989;84:213-6.

10. Kline LB, Morawetz RB, Swaid SN. Indirect injury of the optic nerve. Neurosurgery 1984;14:756-64.

11. Yang WG, Chen CT, Tsay PK, et al. Outcome for traumatic optic neuropathy: surgical versus nonsurgical treatment. Ann Plast Surg 2004;52:36-42. 